\title{
SYNTHESIS AND CHARACTERIZATION OF CYCLOHEXANE-1,3-DIONE DERIVATIVES AND THEIR IN SILICO AND IN VITRO STUDIES ON ANTIMICROBIAL AND BREAST CANCER ACTIVITY
}

\author{
RAJA CHINNAMANAYAKAR ${ }^{1}$, EZHILARASI MR ${ }^{1 *}$, PRABHA B ${ }^{1}$, KULANDHAIVEL $^{2}$
}

${ }^{1}$ Department of Chemistry, Karpagam Academy of Higher Education, Coimbatore, Tamil Nadu, India. ${ }^{2}$ Department of Microbiology, Karpagam Academy of Higher Education, Coimbatore, Tamil Nadu, India. Email: ezhilarasi.au@gmail.com

Received: 29 October 2018, Revised and Accepted: 13 December 2018

\section{ABSTRACT}

Objective: The objective of this study was to evaluate in silico and in vitro anticancer activity for synthesized cyclohexane-1,3-dione derivatives.

Methods: The new series of cyclohexane-1,3-dione derivatives were synthesized based on the Michael addition reaction. Further, the structures of the synthesized compounds were confirmed by Fourier-transform infrared spectroscopy, ${ }^{1} \mathrm{H}$ nuclear magnetic resonance (NMR), and ${ }^{13} \mathrm{C}$ NMR spectral data. Then, the in silico molecular docking studies were carried out using AutoDock tool version 1.5.6 and AutoDock version 4.2.5.1 docking program. The antimicrobial activity was carried out using the agar disk diffusion method, and the in vitro anticancer activity was performed by 3-(4,5-dimethylthiazol-2-yl)-2,5-diphenyltetrazolium bromide (MTT) assay for the synthesized compound.

Results: In silico docking study, compound 5c showed good binding score and binding interactions with selected bacterial proteins and breast cancer protein. Further, compound (5a-5h) was tested for their antimicrobial activity and compound $5 \mathrm{c}$ was only tested for anticancer activity (human breast adenocarcinoma 3,4-methylenedioxyamphetamine-MB-231 cell line). Compound $5 \mathrm{c}$ was found to be the most active one of all the tested compounds. In the MTT assay compound, $5 \mathrm{c}$ showed the $\mathrm{LC}_{50}$ value of $10.31 \pm 0.003 \mu \mathrm{g} / \mathrm{ml}$. In antimicrobial activity, the minimum inhibitory concentration of compound $5 \mathrm{c}$ is $2.5 \mathrm{mg} / \mathrm{ml}$.

Conclusion: An efficient synthesis of biologically active cyclohexane-1, 3-dione derivatives has been developed.

Keywords: Dimedone, Antimicrobial activity, Antifungal activity, Molecular docking studies, Anticancer activity, 3,4-methylenedioxyamphetamineMB-231 cell line.

(C) 2019 The Authors. Published by Innovare Academic Sciences Pvt Ltd. This is an open access article under the CC BY license (http://creativecommons. org/licenses/by/4. 0/) DOI: http://dx.doi.org/10.22159/ajpcr.2019.v12i3.30481

\section{INTRODUCTION}

Cancer is one of the most stressful and life aggressive diseases which implements cruel deaths in the world [1]. It exhibits at least 100 different disease conditions which shares several common symptoms. Cancer is the second leading cause of death in developed countries in spite of its prevention, early detection, and novel therapies. The World Health Organization has warned that nearly 13.1 million people may die of cancer in 2030. Among the women community, breast cancer is the most prevalent type of cancer [2]. The breast cells spread over the body by a process called cancer metastasis. By this process, the organs such as the liver, lungs, brain, and bones get affected and it becomes a major problem affecting the survival of cancer patients. Many therapies were introduced in the recent past to deal with the recurrence of cancer even though drugs and medicines have serious side effects. Hence, the development of drugs to serve as chemoprevention agents is warranted [3].

Heterocyclic compounds play a vital role in the development of pharmacologically active molecules and organic materials [4,5]. The hydroxyl carbonyl compounds prepared by the Claisen-Schmidt reaction between aldehydes and ketone also play an important role in synthetic organic chemistry [6]. Chalcone is a captivating moiety which consists of two aromatic rings linked by enone bridge and it belongs to the flavonoid family. Chalcones show various pharmacological activities such as anticancer, antiviral, antibacterial [7], and antifungal activity [8]. The C-C bond formation has been discovered in the past decades and its applications were reviewed [9-14]. Reactions such as Knoevenagel [15], Henry [16], Aldo [17], and Michael reaction [18] are base catalyzed transformations and are mostly used in organic synthesis. Further, heterocyclic compounds exhibited specific activity and are used in the treatment of many infectious diseases. Liu et al. developed successfully an efficient Michael addition between dimedone and cinnamons using unmodified chiral diphenylethylenediamine (DPEN) [19]. In the fight against the resistant bacterial strains, one of the strategies is the development of new antibacterial drugs affecting the integrity of the bacterial cell wall. According to that, many number of chalcones were evaluated for their anticancer and antibacterial activity. Studies on cyclohexane-1,3-dione remain scattered. Hence, this prompted as to undertake the present work. The antibacterial activity of cyclo-hexanone 1,3-dione compounds mechanism were done by in silico method.

Modern drug design process helps to identify and develop new ligands with a high binding affinity toward a target protein receptor. The molecular docking approaches help to reveal drug-receptor interaction to a greater detail. The study of receptor-ligand interaction is considered as one of the fundamental approaches for rational drug design and so the prediction of such interactions by molecular docking has been gaining importance [20].

The cyclohexane-1,3-dione derivatives have been synthesized by Michael addition method and characterized [21]. The new derivatives of cyclohexane-1,3-dione were synthesized and characterized by Fourier-transform infrared spectroscopy (FT-IR), ${ }^{1} \mathrm{H}$ nuclear magnetic resonance (NMR), and ${ }^{13} \mathrm{C}$ NMR spectral data. Molecular docking studies were carried out against bacterial proteins (1UAG, 3UDI, and 2X50) and cancer proteins (2ZOQ). Finally, the synthesized compounds were screened for antimicrobial activity by agar disk diffusion method and in vitro anticancer activity by 3-(4,5-dimethylthiazol2-yl)-2,5-diphenyltetrazolium bromide (MTT) assay method by 3,4-methylenedioxyamphetamine (MDA)-MB-231 cell line. 


\section{METHODS}

Dimedone (25 g) was purchased from Sigma-Aldrich. The melting points of compounds were determined to open capillary method and the values were uncorrected. The FT-IR spectrum $\left(\mathrm{cm}^{-1}\right)$ was recorded through $\mathrm{KBr}$ in FT-IR spectrometer (model Shimadzu 8400s) in the range of $400-4000 \mathrm{~cm}^{-1}$. The ${ }^{1} \mathrm{H}$ and ${ }^{13} \mathrm{C}$ NMR spectra were recorded by Bruker $400 \mathrm{MHz}$ spectrometer, and chemical shifts are recorded in value (ppm) with tetramethylsilane as an internal standard, as well as $\mathrm{CDCl}_{3}$ used as a solvent.

General procedure for the synthesis of (E)-3-(phenyl)-1-(biphenyl2-yl) 3-arylprop-2-en-1-one derivatives (3a-3h)

$0.1 \mathrm{~mol}$ of various substituted aromatic aldehydes $(1 \mathrm{a}-1 \mathrm{~h})$ and $0.1 \mathrm{~mol}$ of 4-acetyl biphenyl (ketone) were taken in a $100 \mathrm{ml}$ beaker, and to this, approximately added $30 \mathrm{ml}$ of ethanol containing $2 \mathrm{~g}$ of $\mathrm{NaOH}$ pellets. Then, the mixture was stirred well for $3 \mathrm{~h}$ in an ice cold bath after it was poured into the crushed ice containing $500 \mathrm{ml}$ beaker and this reaction mixture was kept into overnight at room temperature. The chalcone precipitated out as solid. Then, it was filtered, dried, and recrystallized from ethanol. The purity of the compound was checked by thin-layer chromatography (TLC) using $\mathrm{CHCl}_{3}$ as a solvent [22].

General procedure for the synthesis of cyclohexane-1,3-dione derivatives (5a-5h)

The dimedone $(0.1 \mathrm{~mol})$ and chalcones $3 \mathrm{a}-3 \mathrm{~h}(0.1 \mathrm{~mol})$ were taken in a round bottom flask containing $30 \mathrm{ml}$ ethanol. After, 1 mole of sodium acetate was added. Then, this reaction mixture was stirred and refluxed for $42 \mathrm{~h}$. After the reaction mixture was poured into $500 \mathrm{ml}$ beaker containing crushed ice and it was kept in overnight at room temperature. Then, it was filtered, dried, and recrystallized from ethanol. The purity of the compound was checked by TLC using $\mathrm{CHCl}_{3}$ as a solvent.

\section{In silico activity}

\section{Molecular docking studies}

Molecular docking studies have been carried out using the AutoDock tools (ADT) version 1.5.6 and AutoDock version 4.2.5.1 docking program.

\section{Preparation of the protein}

The bacterial proteins and cancer protein were downloaded from Protein Data Bank (PDB) with id: 1UAG, 3UDI, 2X50, and 2Z0Q.

\section{Ligand preparation}

Two-dimensional (2D) structure of the cyclohexane-1,3-dione derivatives is drawn using ChemDraw Ultra 8.0 (Chemoffice2002). After that, the chem 3D ultra were used to convert the 2D structure to $3 \mathrm{D}$ structure of the compounds, and the energy is minimized using the semi-empirical AM1 method. All the structures are saved as PDB file format for input to ADT. Finally, all the ligand structures are saved as PDB file format to carry out docking molecular docking in AutoDock Vina.

\section{Grid formation}

A grid box with a dimension of $40 \times 40 \times 40 \mathrm{~A} 3$ in $0.375 \mathrm{~A}$ spacing and centered on $30.473,47.997$, and 9.563 has created around the binding site of protein using ADT. The center of the box was set at ligand center and grid energy calculations have been carried out.

\section{Docking protocol}

Default parameters have been used for auto dock calculations. The energy calculation is done using genetic algorithms. The outputs are exported to Chimera 1.10 and Discovery Studio 4.5 for visual inspection of the binding modes and interaction of the compounds with amino acid residues in the active site [23].

\section{Antimicrobial activity}

The newly synthesized cyclohexane-1,3-dione compounds have been evaluated for their antimicrobial activity. The dimethyl sulfoxide was used as the solvent control of this activity. These studies were carried out by the agar disk diffusion method.

\section{Anticancer activity}

MTT assay

MDA-MB-231 (human breast adenocarcinoma) cell was initially procured from the National Center for Cell Science, Pune, India, and maintained Dulbecco's Modified Eagle's Medium (DMEM) (Sigma Aldrich, USA).

The cell line was cultured in $25 \mathrm{~cm}^{2}$ tissue culture flask with DMEM supplemented with $10 \%$ fetal bovine serum, L-glutamine, and sodium bicarbonate (Merck, Germany) and an antibiotic solution containing penicillin $(100 \mathrm{U} / \mathrm{ml})$, streptomycin $(100 \mu \mathrm{g} / \mathrm{ml})$, and amphotericin B $(2.5 \mu \mathrm{g} / \mathrm{ml})$. Cultured cell lines were kept at $37^{\circ} \mathrm{C}$ in a humidified $5 \%$ $\mathrm{CO}_{2}$ incubator (NBS Eppendorf, Germany).

The viability of cells was evaluated by direct observation of cells by inverted phase contrast microscope and followed by MTT assay method.

\section{Cell seeding in 96-well plate}

Two-day-old confluent monolayer of cells trypsinized and the cells were suspended in $10 \%$ growth medium, and $100 \mu \mathrm{l}$ cell suspension $\left(5 \times 10^{4}\right.$ cells/well) was seeded in 96-well tissue culture plate and incubated at $37^{\circ} \mathrm{C}$ in a humidified $5 \% \mathrm{CO}_{2}$ incubator.

\section{Preparation of compound stock}

Nearly $1 \mathrm{mg}$ of sample was weighed and dissolved in $1 \mathrm{ml}$ DMEM using a cyclomixer. The sample solution was filtered through $0.22 \mu \mathrm{m}$ Millipore syringe filter to ensure the sterility.

\section{Anticancer evaluation}

After $24 \mathrm{~h}$, the growth medium was removed, freshly prepared each compound in 5\% DMEM was five times serially diluted by two-fold dilution $(100 \mu \mathrm{g}, 50 \mu \mathrm{g}, 25 \mu \mathrm{g}, 12.5 \mu \mathrm{g}$ and, $6.25 \mu \mathrm{g})$ in $500 \mu \mathrm{l}$ of $5 \%$ DMEM, and each concentration of $100 \mu \mathrm{l}$ was added in triplicates to the respective wells and incubated at $37^{\circ} \mathrm{C}$ in a humidified $5 \% \mathrm{CO}_{2}$ incubator. Non-treated control cells were also maintained.

\section{Anticancer assay by MTT method}

About $15 \mathrm{mg}$ of MTT (Sigma, M-5655) was reconstituted in $3 \mathrm{ml}$ PBS until completely dissolved and sterilized by filter sterilization. After $24 \mathrm{~h}$ of the incubation period, the sample content in wells was removed and $30 \mu \mathrm{l}$ of reconstituted MTT solution was added to all test and cell control wells; the plate was gently shaken well and then incubated at $37^{\circ} \mathrm{C}$ in a humidified $5 \% \mathrm{CO}_{2}$ incubator for $4 \mathrm{~h}$. After the incubation period, the supernatant was removed and $100 \mu \mathrm{l}$ of MTT solubilization solution (dimethyl sulfoxide, Sigma-Aldrich, USA) was added, and the wells were mixed gently by pipetting up and down to solubilize the formazan crystals. The absorbance values were measured using microplate reader at a wavelength of $540 \mathrm{~nm}$ [24].

The percentage of growth inhibition was calculated using the following formula:

$$
\% \text { of viability }=\frac{\text { Mean OD } \times 100}{\text { Mean OD of control group }}
$$

\section{RESULTS AND DISCUSSION}

\section{Chemistry}

In the present research work, the new series of cyclohexane-1,3-dione derivatives $(5 a-5 h)$ were synthesized, which is shown in Scheme 1 . The first step in Scheme 1 is the condensation reaction between substituted aldehydes and 4-acetyl biphenyl in the presence of a base to give compound (3a-3h). Finally, the compounds were recrystallized 


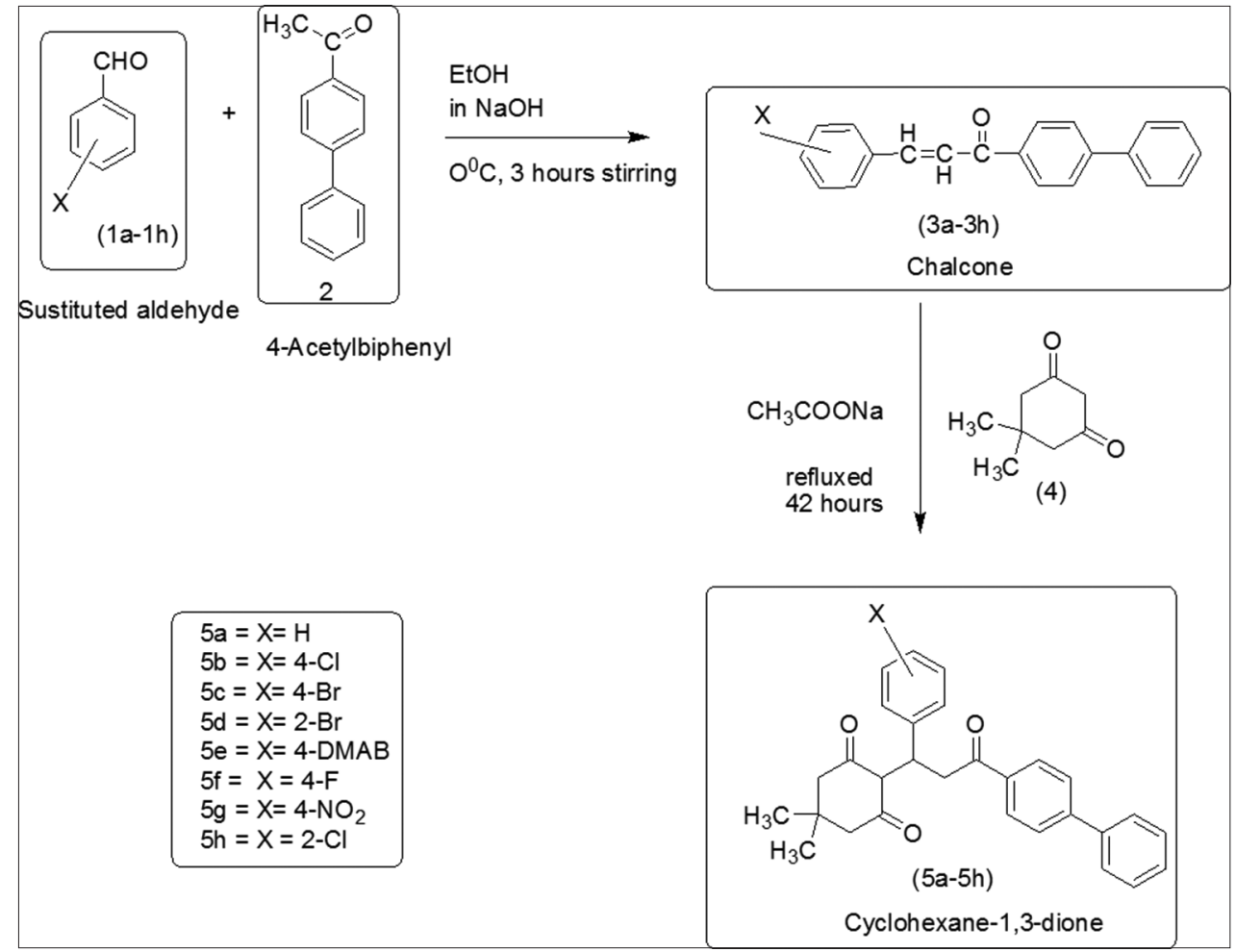

Scheme 1: Synthetic pathway for cyclohexane-1,3-dione derivatives (5a-5h)

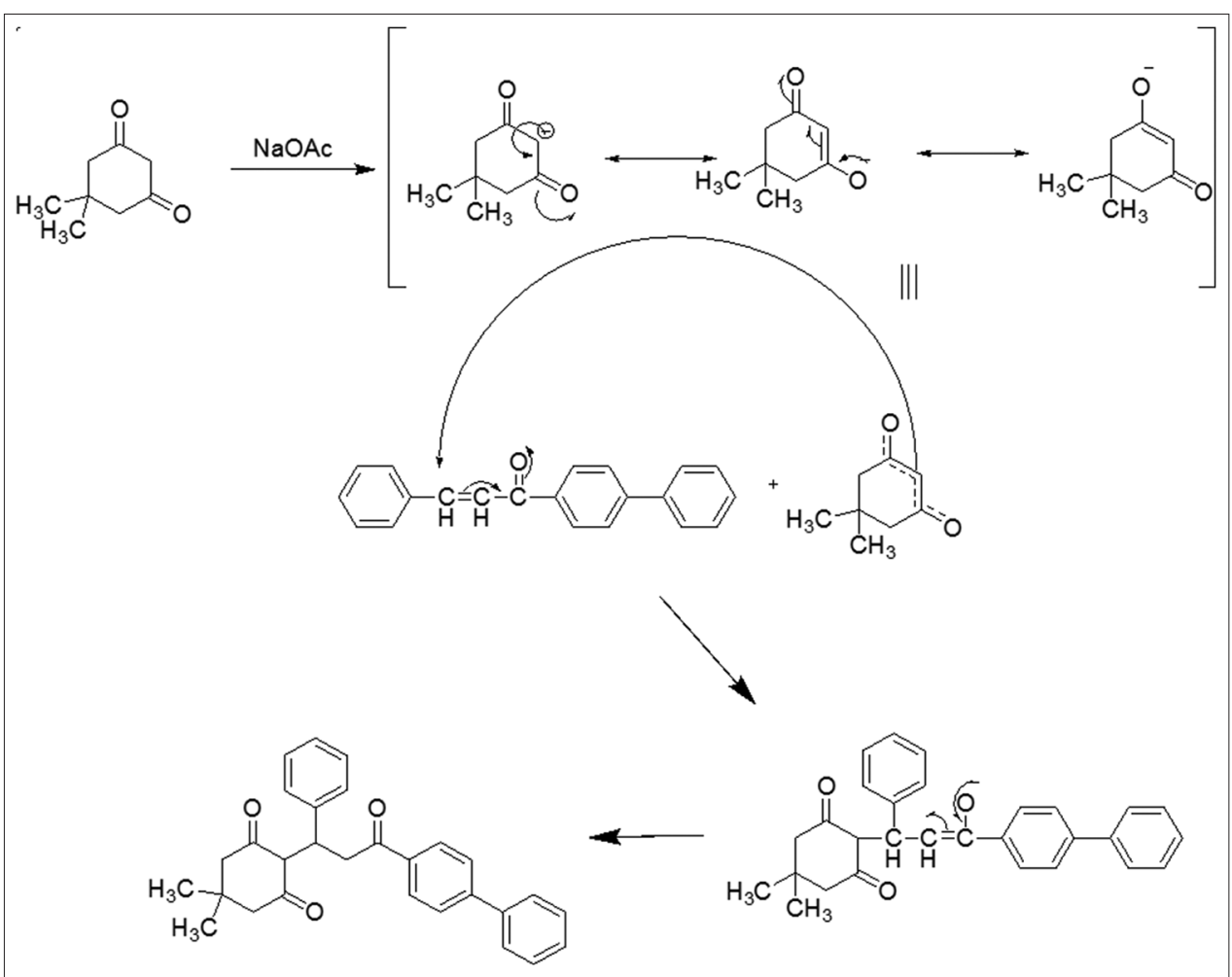

Scheme 2: Possible mechanism for the formation of cyclohexane-1,3-dione derivatives (5a-5h)

by using ethanol solvent. The chalcones (3a-3h) react with dimedone in the presence of sodium acetate by Michael addition reaction to give cyclohexane-1,3-dione derivatives. The cyclohexane-1,3-dione derivatives were purified by column chromatography using $\mathrm{CHCl}_{3}$ as the solvent. The structure of the synthesized compounds (5a-5h) was confirmed by spectral techniques such as FT-IR, ${ }^{1} \mathrm{H}$ NMR, and ${ }^{13} \mathrm{C}$ NMR. The possible mechanism for this reaction is shown in Scheme 2.
5, 5-dimethyl-2-(3-oxo-1-diphenyl-3-phenylpropyl) cyclohexane1,3-dione (5a)

Yield 69\%; white solid; molecular formula; $\mathrm{C}_{29} \mathrm{H}_{28} \mathrm{O}_{3}$; IR $(\mathrm{KBr})$ : $\mathrm{C}=0 \quad(1705.07,1678.07,1598.99), 3059.10,3034.03,2956.87$ (Ar$\mathrm{CH}), 1487.12(\mathrm{C}=\mathrm{C}), 694.37,729.09,759.95,833.25 ;{ }^{1} \mathrm{H} \mathrm{NMR}\left(\mathrm{CDCl}_{3}\right.$, $400 \mathrm{MHz}$ ): 1.032 (s, 3H), 1.096 (s, 3H), 2.405-2.448 (m, 4H, H-6 and $\mathrm{H}-8) ; 2.57 \mathrm{ppm}\left(\mathrm{dd}, \mathrm{J}_{2^{\prime}, 2^{\prime} \mathrm{b}}=15.2 \mathrm{~Hz}, \mathrm{~J}_{2^{\prime}, 3^{3}}=3.2,1 \mathrm{H}, \mathrm{H}-2^{\prime} \mathrm{a}\right) ; 3.64 \mathrm{ppm}$ 
(dd, $\left.\mathrm{J}_{2^{\prime} \mathrm{b}, 2^{\prime} \mathrm{a}}=15.8 \mathrm{~Hz}, \mathrm{~J}_{2^{\prime} \mathrm{b}, 3^{\prime}}=3.8 \mathrm{~Hz}, 1 \mathrm{H}, \mathrm{H}-2^{\prime} \mathrm{b}\right) ; 4.41 \mathrm{ppm}\left(\mathrm{dd}, \mathrm{J}_{3,2^{\prime} \mathrm{a}}=7 \mathrm{~Hz}\right.$, $\left.\mathrm{J}_{3,2^{2} \mathrm{~b}}=4.6 \mathrm{~Hz}, \mathrm{H}-3^{\prime}\right) ; 7.259-7.958$ (m, Ar-H). ${ }^{13} \mathrm{C} \mathrm{NMR},\left(\mathrm{CDCl}_{3}, 100 \mathrm{MHz}\right)$; $30.539\left(\mathrm{CH}_{3}\right)$ at $\mathrm{C}-5,30.639\left(\mathrm{CH}_{3}\right)$ at $\mathrm{C}-5,38.952(\mathrm{C}-5), 26.076\left(\mathrm{C}-3^{\prime}\right)$, 45.724 (C-2'), 52.518 (C-4), 53.387 (C-6), 100.361 (C-2), 196.638 (C-1'), 202.815 (C-3), 203.895 (C-1), Ar-C (127.247-129.199), IPSO carbon $(146.232,139.742,136.985,134.892)$.

\section{2-(1-(4-chlorophenyl)-3-oxo-3-diphenylpropyl)-5,} 5-dimethylcyclohexane-1,3-dione (5b)

Yield 86\%; white solid; molecular formula; $\mathrm{C}_{29} \mathrm{H}_{27} \mathrm{ClO}_{3}$; IR (KBr): $\mathrm{C}=0(1701.22,1600.92,1556.55), 3057.17,3034.03,2958.80$ (Ar-CH), 1489.05 (C=C), 698.23, 758.02, 833.25; ${ }^{1} \mathrm{H}$ NMR $\left(\mathrm{CDCl}_{3}, 400 \mathrm{MHz}\right): 0.978$ (s, 3H), 1.016 (s, 3H), 2.419-2.462 (m, 4H, H-6 and H-8); 2.58 ppm (dd, $\left.\mathrm{J}_{2^{\prime}, 2^{\prime} \mathrm{b}^{\prime}}=14.8 \mathrm{~Hz}, \mathrm{~J}_{2^{\prime} \mathrm{a}, 3^{\prime}}=3.6 \mathrm{~Hz}, 1 \mathrm{H}, \mathrm{H}-2^{\prime} \mathrm{a}\right) ; 3.64 \mathrm{ppm}\left(\mathrm{dd}, \mathrm{J}_{2^{\prime} \mathrm{b}, 2^{\prime} \mathrm{a}}=16.6 \mathrm{~Hz}\right.$, $\left.\mathrm{J}_{2^{\prime} \mathrm{b}_{3} 3^{\prime}}=2.6 \mathrm{~Hz}, 1 \mathrm{H}, \mathrm{H}-2^{\prime} \mathrm{b}\right) ; 4.38 \mathrm{ppm}\left(\mathrm{dd}, \mathrm{J}_{3^{\prime}, \mathrm{z}^{\prime} \mathrm{a}}=7.6 \mathrm{~Hz}, \mathrm{~J}_{3,2^{\prime} \mathrm{b}^{\prime}}=4.4 \mathrm{~Hz}, \mathrm{H}-3^{\prime}\right)$; 7.259-7.958 (m, Ar-H). ${ }^{13} \mathrm{C} \mathrm{NMR}^{\mathrm{CDCl}} \mathrm{CD}_{3}, 400 \mathrm{MHz}, \delta ; 30.497\left(\mathrm{CH}_{3}\right), 30.669$ $\left(\mathrm{CH}_{3}\right), 31.162$ (C-5), 26.049 (C-3'), 44.998 (C-2'), 52.461 (C-4), 53.334 (C-6), 116.542 (C-2), 196.358 (C-1'), 201.749 (C-1), 202.522 (C-3), Ar-C (127.157-135.475), IPSO carbon (146.851, 146.401, 140.533, 139.683).

\section{2-(1-(4-bromo phenyl)-3-oxo-3-diphenylpropyl)-5, 5-dimethyl cyclohexane-1,3-dione (5c)}

Yield 84\%; white solid; molecular formula; $\mathrm{C}_{29} \mathrm{H}_{27} \mathrm{BrO}_{3}$; IR $(\mathrm{KBr}$ ): $\mathrm{C}=0$ (1703.14, 1598.99, 1550.77), 3024.38, 2956.87 (Ar-CH), 1485.19 (C=C), 696.30, 725.23, 761.88, 835.18; ${ }^{1} \mathrm{H}$ NMR ( $\left.\mathrm{CDCl}_{3} 400 \mathrm{MHz}\right): 0.879$ $(\mathrm{s}, 3 \mathrm{H}), 1.255$ (s, 3H), 2.422-2.465 (m, 4H, H-6 and H-8), 2.58 ppm (dd, $\left.\mathrm{J}_{2^{\prime} \mathrm{a}, \mathrm{z}^{\prime} \mathrm{b}}=15.2 \mathrm{~Hz}, \mathrm{~J}_{2^{\prime} \mathrm{a}, 3^{\prime}}=3.2 \mathrm{~Hz}, 1 \mathrm{H}, \mathrm{H}-2^{\prime} \mathrm{a}\right) ; 3.63 \mathrm{ppm}\left(\mathrm{dd}, \mathrm{J}_{2^{\mathrm{b}}, 2^{\prime} \mathrm{a}}=18.9 \mathrm{~Hz}\right.$, $\left.\mathrm{J}_{2^{\prime} \mathrm{b}, 3^{\prime}}=3.9 \mathrm{~Hz}, 1 \mathrm{H}, \mathrm{H}-2^{\prime} \mathrm{b}\right) ; 4.37 \mathrm{ppm}\left(\mathrm{dd}, \mathrm{J}_{3,2^{\prime} \mathrm{a}}=7.4 \mathrm{~Hz}, \mathrm{~J}_{3^{\prime}, 2^{\prime} \mathrm{b}}=4.2 \mathrm{~Hz}, \mathrm{H}-3^{\prime}\right.$ ); 7.234-7.950 (m, ph-H). ${ }^{13} \mathrm{C}$ NMR, $\left(\mathrm{CDCl}_{3}, 400 \mathrm{MHz}\right), \delta ; 30.686\left(\mathrm{CH}_{3}\right)$ at $\mathrm{C}-5,30.503\left(\mathrm{CH}_{3}\right)$ at $\mathrm{C}-5,38.884(\mathrm{C}-5), 26.059\left(\mathrm{C}-3^{\prime}\right), 45.040\left(\mathrm{C}-2^{\prime}\right)$, 52.444 (C-4), 53.323 (C-6), 100.093 (C-2), 196.322 (C-1'), 202.531 (C-1), 203.522 (C-3), Ar-C (122.331-131.889), IPSO carbon (146.412, $139.677,135.980,134.696)$.

\section{2-(1-(2-bromo phenyl)-3-oxo-3-diphenylpropyl)-5, 5-dimethyl} cyclohexane-1,3-dione (5d)

Yield 78\%; white solid; molecular formula; $\mathrm{C}_{29} \mathrm{H}_{27} \mathrm{BrO}_{3}$; IR (KBr): $\mathrm{C}=0$ (1705.07, 1691.57, 1598.99), 2954.95, 2922.16 (Ar-CH), 1481.33 $(\mathrm{C}=\mathrm{C}), 694.37,731.02,765.74,839.03 ;{ }^{1} \mathrm{H}$ NMR $\left(\mathrm{CDCl}_{3}, 400 \mathrm{MHz}\right): 1.116$ $(\mathrm{s}, 3 \mathrm{H}), 1.159$ (s, 3H), 2.354-2.476 (m, 4H, H-6 and H-8), 2.58 ppm (dd, $\left.\mathrm{J}_{2^{\prime}, 2^{\prime} b^{\prime}}=19.4 \mathrm{~Hz}, \mathrm{~J}_{2^{\prime} \mathrm{a}, 3^{\prime}}=3.8 \mathrm{~Hz}, 1 \mathrm{H}, \mathrm{H}-2^{\prime} \mathrm{a}\right), 3.61 \mathrm{ppm}\left(\mathrm{dd}, \mathrm{J}_{\mathrm{z}^{\prime} \mathrm{b}, \mathrm{z}^{\prime} \mathrm{a}}=18.4 \mathrm{~Hz}\right.$, $\left.\mathrm{J}_{2^{\prime}, 3_{3}}=3.6 \mathrm{~Hz}, 1 \mathrm{H}, \mathrm{H}-2^{\prime} \mathrm{b}\right) ; 4.92 \mathrm{ppm}\left(\mathrm{dd}, \mathrm{J}_{3,2^{\prime} \mathrm{a}}=8.4 \mathrm{~Hz}, \mathrm{~J}_{3,2^{\prime} \mathrm{b}^{\prime}}=3.2 \mathrm{~Hz}, \mathrm{H}-\mathrm{H}^{\prime}\right) ; 6.863-$ 7.892 (m, ph-H). ${ }^{13} \mathrm{C} \mathrm{NMR,}\left(\mathrm{CDCl}_{3}, 400 \mathrm{MHz}\right) ; 28.608\left(\mathrm{CH}_{3}\right)$ at C-5, 30.745 $\left(\mathrm{CH}_{3}\right)$ at C-5, 38.884 (C-5), 27.869 (C-3'), 42.347 (C-2'), 43.420 (C-4), 50.780 (C-6), 116.134 (C-2), 197.565 (C-1'), 200.473 (C-1), 203.589 (C-3), Ar-C (123.745-131.512), IPSO carbon $(146.120,134.814,132.107,131.910)$.

\section{2-(1-(4-dimethylamino phenyl)-3-oxo-3-diphenylpropyl)-5, 5-dimethylcyclohexane-1,3-dione (5e)}

Yield 70\%; white solid; molecular formula; $\mathrm{C}_{31} \mathrm{H}_{33} \mathrm{NO}_{3}$; IR (KBr): $\mathrm{C}=0$ (1676.14, 1662.85, 1516.05), 3026.31, $2953.02(\mathrm{Ar}-\mathrm{CH}), 1458.18$ $(\mathrm{C}=\mathrm{C}), 692.44,738.74,759.95,819.75 ;{ }^{1} \mathrm{H}$ NMR $\left(\mathrm{CDCl}_{3}, 400 \mathrm{MHz}\right): 1.012$ $(\mathrm{s}, 3 \mathrm{H}), 1.049(\mathrm{~s}, 3 \mathrm{H}), 2.283-2.435(\mathrm{~m}, 4 \mathrm{H}, \mathrm{H}-6$ and $\mathrm{H}-8), 2.89 \mathrm{ppm}$ (dd, $\left.\mathrm{J}_{2^{\prime} \mathrm{a}, 2^{\prime} \mathrm{b}}=11.8 \mathrm{~Hz} \mathrm{~J}_{2^{\prime} \mathrm{a}, 3^{\prime}}=7.4 \mathrm{~Hz}, 1 \mathrm{H}, \mathrm{H}-2^{\prime} \mathrm{a}\right), 3.60 \mathrm{ppm}\left(\mathrm{dd}, \mathrm{J}_{2^{\mathrm{b}}, 2^{\prime} \mathrm{a}}=6.8 \mathrm{~Hz}\right.$,

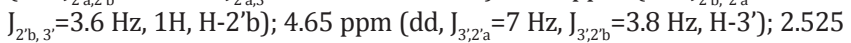
$(\mathrm{s}, 3 \mathrm{H}), 2.5497$ (s,3H); 7.197-7.703 (m, Ar-H). ${ }^{13} \mathrm{C} \mathrm{NMR},\left(\mathrm{CDCl}_{3}, 400 \mathrm{MHz}\right)$; $27.857\left(\mathrm{CH}_{3}\right)$ at C-5, $28.250\left(\mathrm{CH}_{3}\right)$ at C-5, $33.455(\mathrm{C}-5), 22.145\left(\mathrm{C}-3^{\prime}\right), 46.143$ (C-2'), 54.070 (C-4), 56.823 (C-6), 108.423 (C-2), 195.565 (C-1'), 201.763 $(\mathrm{C}-1), 202.489(\mathrm{C}-3), 40.717\left(\mathrm{CH}_{3}\right)$ at N $\left(\mathrm{CH}_{3}\right)_{2}, 40.860\left(\mathrm{CH}_{3}\right)$ at N $\left(\mathrm{CH}_{3}\right)_{2}, \mathrm{Ar}-\mathrm{C}$ (112.295-129.512), IPSO carbon $(149.005,146.421,139.766,135.115)$.

\section{2-(1-(4-fluorophenyl)-3-oxo-3-diphenylpropyl)-5, 5-dimethyl cyclohexane-1,3-dione derivative (5f)}

Yield 74\%; white solid; molecular formula; $\mathrm{C}_{29} \mathrm{H}_{27} \mathrm{FO}_{3}$; IR (KBr): $\mathrm{C}=\mathrm{O}(1681.43,1698.39,1703.69), 3058.41(\mathrm{Ar}-\mathrm{CH}), 1463.72(\mathrm{C}=\mathrm{C})$, 687.90, 712.40, 740.38, 803.17; ${ }^{1} \mathrm{H}$ NMR ( $\left.\mathrm{CDCl}_{3}, 400 \mathrm{MHz}\right): 1.093$
(s,3H), $1.068(\mathrm{~s}, 3 \mathrm{H}), 2.273-2.439(\mathrm{~m}, 4 \mathrm{H}, \mathrm{H}-6$ and $\mathrm{H}-8), 2.75 \mathrm{ppm}(\mathrm{dd}$, $\left.\mathrm{J}_{2^{\prime} \mathrm{a}, 2^{\prime} \mathrm{b}}=11.6 \mathrm{~Hz}, \mathrm{~J}_{2^{\prime} \mathrm{a}, 3^{\prime}}=7.1 \mathrm{~Hz}, 1 \mathrm{H}, \mathrm{H}-2^{\prime} \mathrm{a}\right) ; 3.67 \mathrm{ppm}\left(\mathrm{dd}, \mathrm{J}_{2^{\prime}, 2^{\prime} \mathrm{a}}=7.3 \mathrm{~Hz}\right.$, $\left.\mathrm{J}_{2^{\prime}, 3^{\prime},}=3.8 \mathrm{~Hz}, 1 \mathrm{H}, \mathrm{H}-2^{\prime} \mathrm{b}\right) ; 4.61 \mathrm{ppm}\left(\mathrm{dd}, \mathrm{J}_{3^{\prime}, 2^{\prime} \mathrm{a}}=7.5 \mathrm{~Hz}, \mathrm{~J}_{3^{\prime} \mathrm{z}^{\prime} \mathrm{b}}=3.6 \mathrm{~Hz}, \mathrm{H}-3^{\prime}\right)$; 6.893-7.719 (m, Ar-H). ${ }^{13} \mathrm{C} \mathrm{NMR,}\left(\mathrm{CDCl}_{3}, 400 \mathrm{MHz}\right) ; 27.38\left(\mathrm{CH}_{3}\right)$ at C-5, $29.71\left(\mathrm{CH}_{3}\right)$ at C-5, 32.13 (C-5), 23.739 (C-3'), 41.016 (C-2'), 55.910 (C-4), 58.711 (C-6), 114.810 (C-2), 198.513 (C-1'), 203.901 (C-1), 204.171 (C-3), Ar-C (118.873-128.501), IPSO carbon (147.59, 146.30, 144.81, 139.91).

2-(1-(4-nitrophenyl)-3-oxo-3-diphenylpropyl)-5, 5-dimethyl cyclohexane-1,3-dione derivative $(5 \mathrm{~g})$

Yield 77\%; white solid; molecular formula; $\mathrm{C}_{29} \mathrm{H}_{27} \mathrm{NO}_{5}$; IR (KBr): $\mathrm{C}=0$ (1699.17, 1703.82, 1598.41), 3089.51, 2086.61 (Ar-CH), 1489.07 $(\mathrm{C}=\mathrm{C}), 683.81,724.23,759.32,855.69 ;{ }^{1} \mathrm{H}$ NMR $\left(\mathrm{CDCl}_{3}, 400 \mathrm{MHz}\right): 0.936$ (s,3H), $1.170(\mathrm{~s}, 3 \mathrm{H}), 2.419-2.460(\mathrm{~m}, 4 \mathrm{H}, \mathrm{H}-6$ and H-8), $2.59 \mathrm{ppm}(\mathrm{dd}$, $\left.\mathrm{J}_{2^{\prime} \mathrm{a}, \mathrm{z}^{\prime} \mathrm{b}}=15.4 \mathrm{~Hz}, \mathrm{~J}_{2^{\prime} \mathrm{a}, 3^{\prime}}=3.7 \mathrm{~Hz}, 1 \mathrm{H}, \mathrm{H}-2 \mathrm{a}\right)$; $3.67 \mathrm{ppm}\left(\mathrm{dd}, \mathrm{J}_{2^{\prime} \mathrm{b}, 2^{\prime} \mathrm{a}}=18.3 \mathrm{~Hz}\right.$, $\left.\mathrm{J}_{2^{\prime}, 3_{3}}=3.7 \mathrm{~Hz}, 1 \mathrm{H}, \mathrm{H}-2^{\prime} \mathrm{b}\right) ; 4.51 \mathrm{ppm}\left(\mathrm{dd}, \mathrm{J}_{3,2^{\prime} \mathrm{a}}=7.1 \mathrm{~Hz}, \mathrm{~J}_{3,2^{\prime} \mathrm{b}}=4.3 \mathrm{~Hz}, \mathrm{H}-3^{\prime}\right)$; 7.137-7.943 (m, Ar-H). ${ }^{13} \mathrm{C}$ NMR, $\left(\mathrm{CDCl}_{3}, 400 \mathrm{MHz}\right), \delta, 31.684\left(\mathrm{CH}_{3}\right)$ at $\mathrm{C}-5,31.592\left(\mathrm{CH}_{3}\right)$ at $\mathrm{C}-5,39.730(\mathrm{C}-5), 27.941\left(\mathrm{C}-3^{\prime}\right), 44.142\left(\mathrm{C}-2^{\prime}\right)$, 54.041 (C-4), 55.767 (C-6), 112.42 (C-2), 195.672 (C-1'), 201.337 (C-1), 203.741 (C-3). Ar-C (120.08-129.31), IPSO carbon (144.83, 141.09, $139.03,139.17)$.

2-(1-(2-chlorophenyl)-3-oxo-3-diphenylpropyl)-5, 5-dimethyl cyclohexane-1,3-dione derivative (5h)

Yield 82\%; white solid; molecular formula; $\mathrm{C}_{29} \mathrm{H}_{27} \mathrm{ClO}_{3}$; IR (KBr): $\mathrm{C}=0$ (1699.24, 1607.83, 1554.55), 3087.83, 3013.90, 2986.41 (Ar-CH), $1486.20(\mathrm{C}=\mathrm{C}), 694.01,763.03,85409 ;{ }^{1} \mathrm{H}$ NMR $\left(\mathrm{CDCl}_{3}, 400 \mathrm{MHz}\right): 0.971$ (s,3H), $1.013(\mathrm{~s}, 3 \mathrm{H}), 2.407-2.493$ (m, 4H, H-6 and H-8), 2.57 ppm (dd, $\left.\mathrm{J}_{2^{\prime} \mathrm{a}, 2^{\prime} \mathrm{b}}=14.3 \mathrm{~Hz}, \mathrm{~J}_{2^{\prime} \mathrm{a}, 3^{\prime}}=3.1 \mathrm{~Hz}, 1 \mathrm{H}, \mathrm{H}-2^{\prime} \mathrm{a}\right) ; 3.61 \mathrm{ppm}\left(\mathrm{dd}, \mathrm{J}_{2^{\prime} \mathrm{b}, 2^{\prime} \mathrm{a}}=16.7 \mathrm{~Hz}\right.$, $\left.\mathrm{J}_{2^{\prime} \mathrm{b}_{3}, 3^{\prime}}=3.1 \mathrm{~Hz}, 1 \mathrm{H}, \mathrm{H}-2^{\prime} \mathrm{b}\right) ; 4.47 \mathrm{ppm}\left(\mathrm{dd}, \mathrm{J}_{3,2^{\prime} \mathrm{a}}=7.4 \mathrm{~Hz}, \mathrm{~J}_{3,2^{\prime} \mathrm{b}}=4.9 \mathrm{~Hz}, \mathrm{H}-3^{\prime}\right)$; 7.194-7.938 (m, Ar-H). ${ }^{13} \mathrm{C}$ NMR, $\mathrm{CDCl}_{3}, 400 \mathrm{MHz}, \delta ; 30.731\left(\mathrm{CH}_{3}\right)$, $30.971\left(\mathrm{CH}_{3}\right), 31.738$ (C-5), $26.072\left(\mathrm{C}-3^{\prime}\right), 45.988\left(\mathrm{C}-2^{\prime}\right), 51.653(\mathrm{C}-4)$, 53.413 (C-6), 117.40 (C-2), 196.19 (C-1'), 201.028 (C-1), 203.627 (C$3)$ Ar-C (123.740-134.891), IPSO carbon (145.937, 143.970, 140.71, 139.99).

\section{Docking studies of cyclohexane-1, 3-dione derivatives (5a-5h)}

In the present study, in silico molecular docking studies of cyclohexane1,3-dione derivatives $(5 a-5 h)$ against bacterial proteins (PDB id: 1UAG, 3UDI, and 2X50) and breast cancer protein (PDB id: 2ZOQ) have been carried out using ADT version 1.5.6 and AutoDock version 4.2.5.1 docking program. The molecular docking studies are reported in terms of binding affinity score and the compound which have a better interactions had a lower affinity score. In the ligand, cyclohexane-1,3-done derivatives (5a-5h) were individual, docked with bacterial proteins. Docking results are shown in Table 1. From the table, cyclohexane-1,3-dione derivatives (5a-5h) exhibit good docking scores compared to standard drug (amoxicillin). Based on the docking score, hydrophobic and hydrophilic interaction, cyclohexane1,3-dione derivatives ( $5 \mathrm{a}-5 \mathrm{~h}$ ) show better binding affinity compared to the standard drug. The proteins IUAG, 3UDI, and 2X50 were involved in the cell wall synthesis mechanism. Molecular docking studies show that this cyclohexane-1,3-dione derivatives bind well in the active site pocket of bacterial proteins and interact with the active site of amino acid residues. The best compound of this cyclohexane-1,3-dione derivatives has been explained.

\section{Binding affinity value}

Finally, the binding affinity value, conventional hydrogen bond, hydrophobic interaction such as alkyl and pi-alkyl interactions, and other interactions were obtained. Cyclohexane-1,3-dione derivatives showed good interaction with the studied proteins. Compound $5 \mathrm{c}$ showed good binding score with 1 UAG $(-9.3 \mathrm{kcal} / \mathrm{mol})$, 3UDI $(-9.6 \mathrm{kcal} / \mathrm{mol})$, and $2 \times 50(-9.4 \mathrm{kcal} / \mathrm{mol})$ compared with other synthesized compound of this series (5a-5h) and standard drug. Other synthesized compounds (5a-5h) binding affinity score are shown in Table 1. 


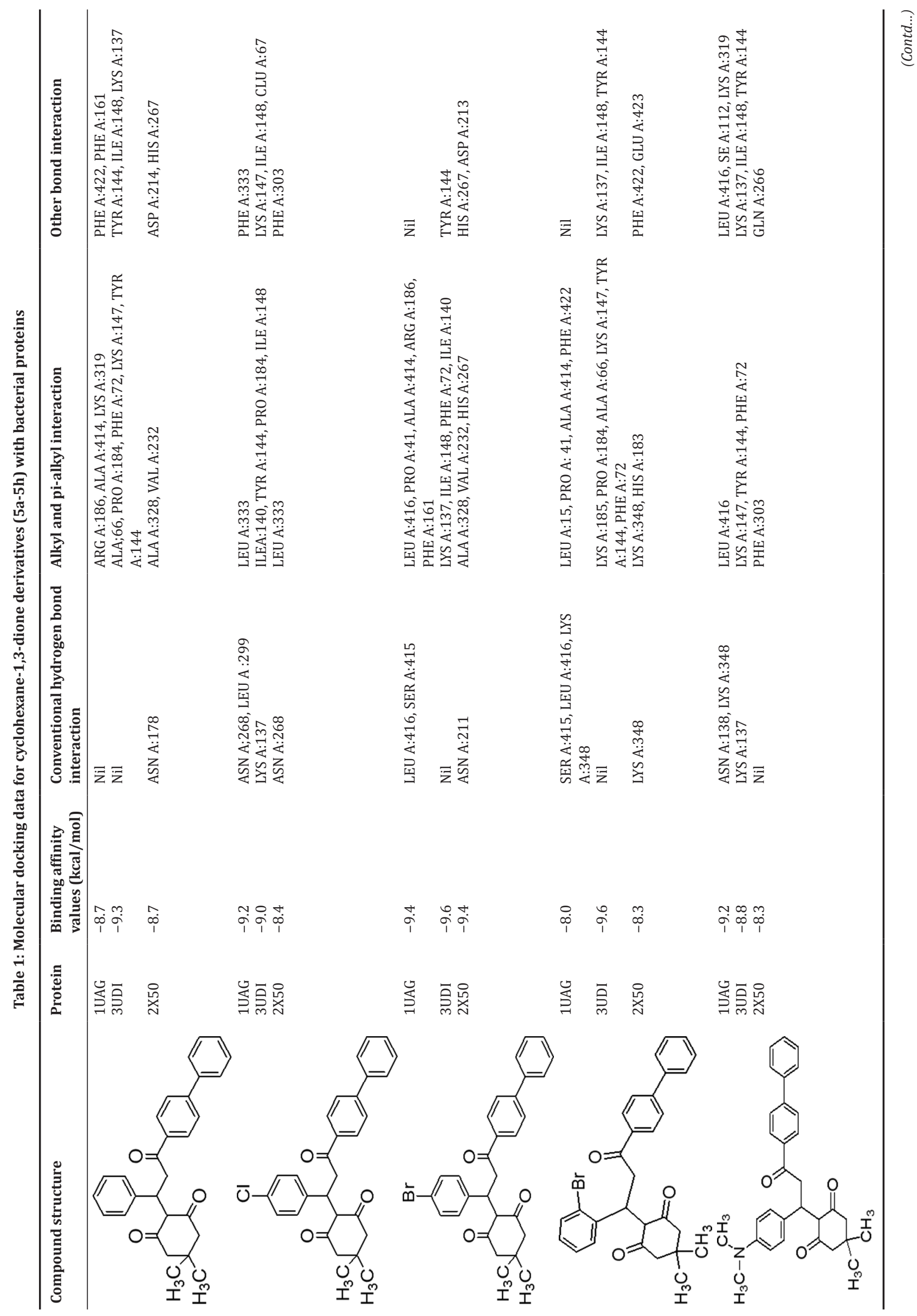




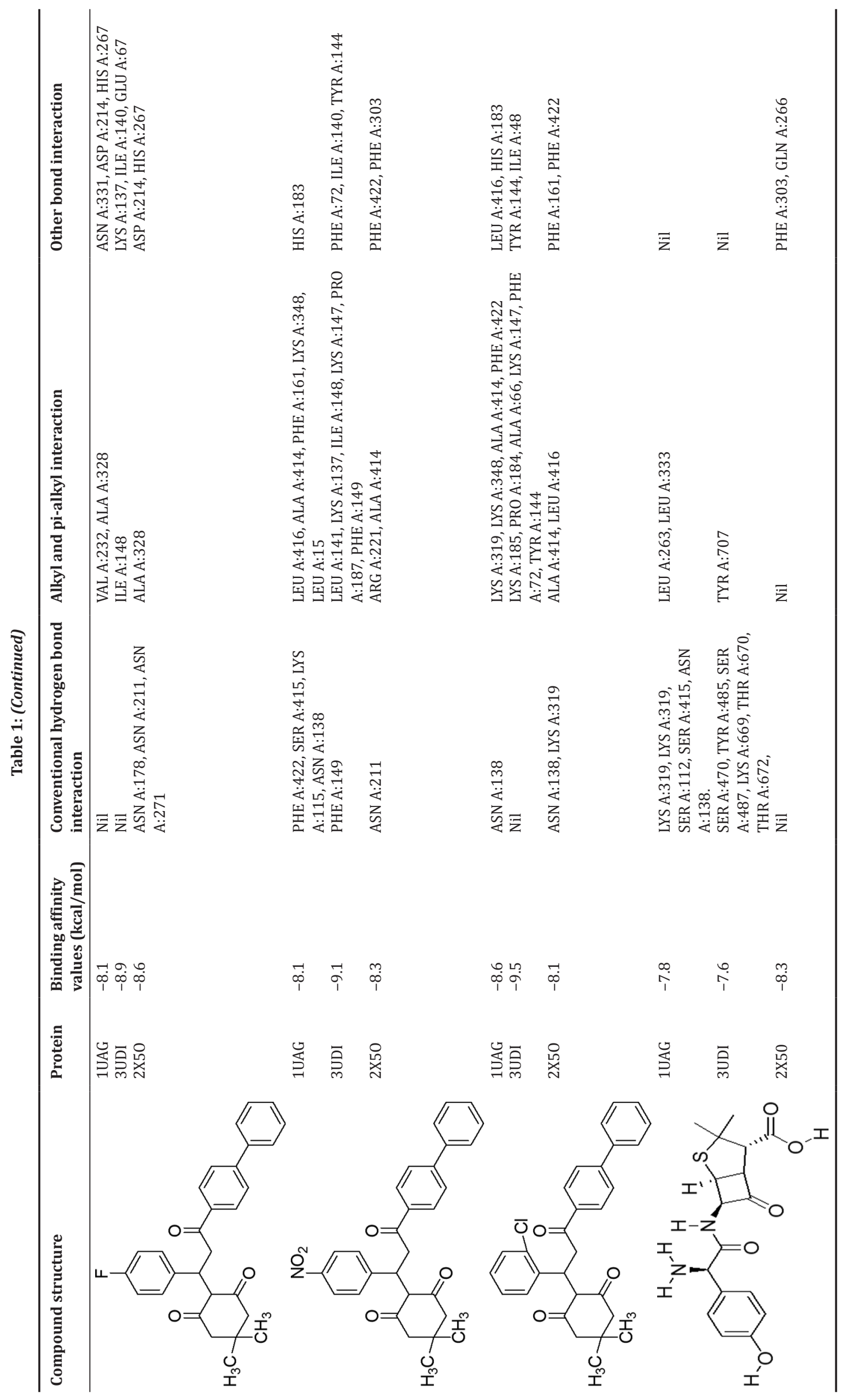




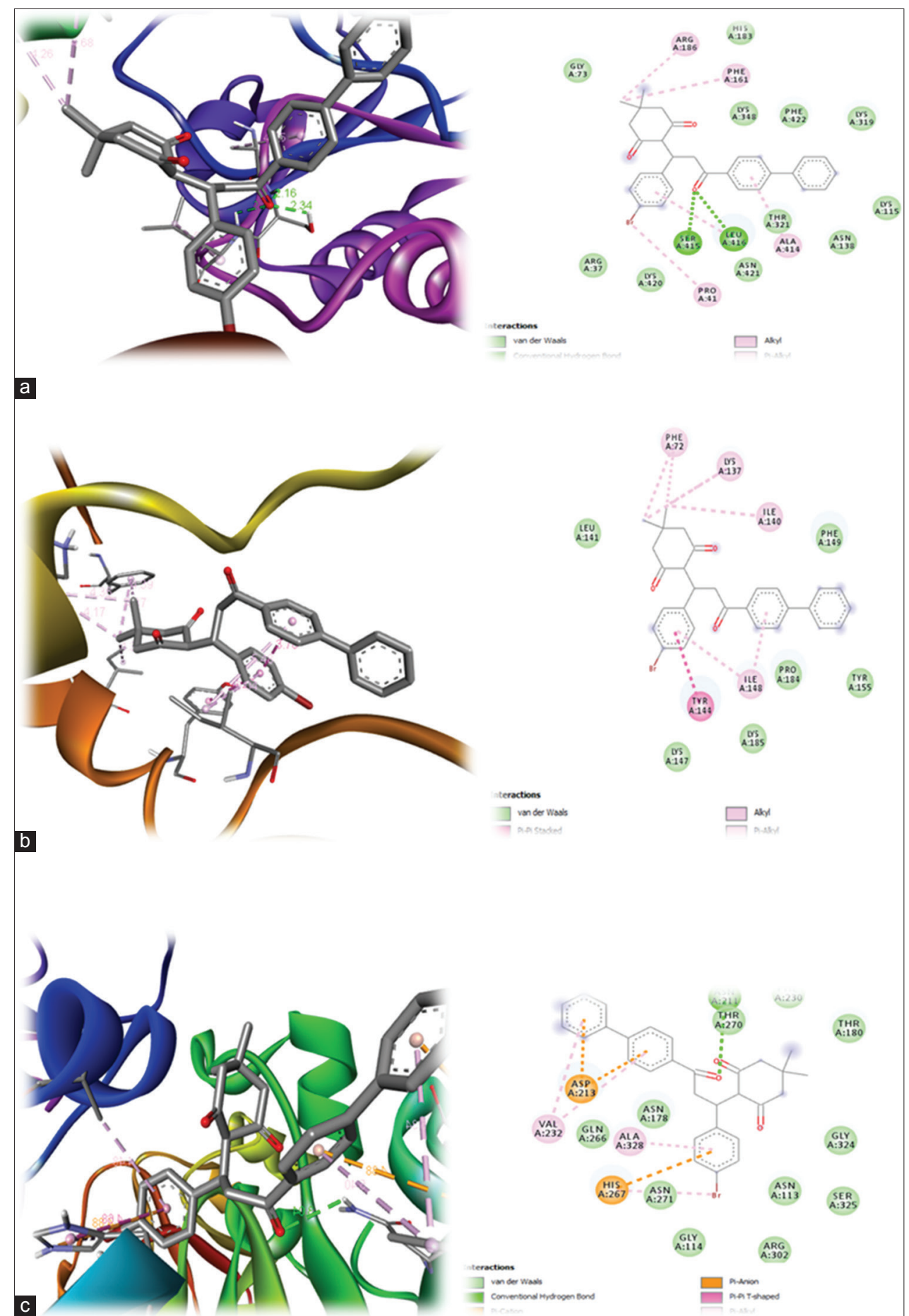

Fig. 1: (a) Two-dimensional (2D) and three-dimensional (3D) images of compound 5c docked with 1UAG protein. (b) 2D and 3D images of compound 5c docked with 3UDI protein. (c) 2D and 3D images of compound 5c docked with $2 \mathrm{X} 50$ protein

\section{Conventional hydrogen bond interaction}

Based on high binding affinity value, compound 5 c has two conventional hydrogen bond interactions (LEU A: 416 and SER A: 415) with carbonyl moiety of the biphenyl ring (1UAG); compound 5 c has no hydrogen bond interaction with 3UDI protein; compound $5 c$ has only one hydrogen bond interaction (ASN A: 211) with carbonyl moiety of the biphenyl ring (2X50). Other synthesized compounds (5a-5h) conventional hydrogen bond interactions are shown in Table 1.

\section{Hydrophobic interaction}

Based on high binding affinity value, compound $5 \mathrm{c}$ has five hydrophobic interactions LEU A: 416, PRO A: 41, ALA A: 414, ARG A: 186, and
PHE A: 161 with 1 UAG protein; compound $5 \mathrm{c}$ has four conventional hydrogen bond interactions LYS A: 137, ILE A: 148, PHE A: 72, and ILE A: 140 with 3UDI protein; compound $5 \mathrm{c}$ has three hydrophobic interactions ALA A: 328 , VAL A: 232, and HIS A: 267 with 2 X50 protein. Other synthesized compounds (5a-5h) hydrophobic interactions are shown in Table 1.2D and 3D images of compound 5c are shown in Fig. 1.

The new series of cyclohexane-1,3-dione derivatives (5a-5h) were subjected to molecular docking studies against breast cancer protein 2ZOQ. Compound $5 \mathrm{c}$ has high binding affinity score than other cyclohexane-1,3-dione derivatives of this series. For that reason, that compound was performed in vitro anticancer activity against 


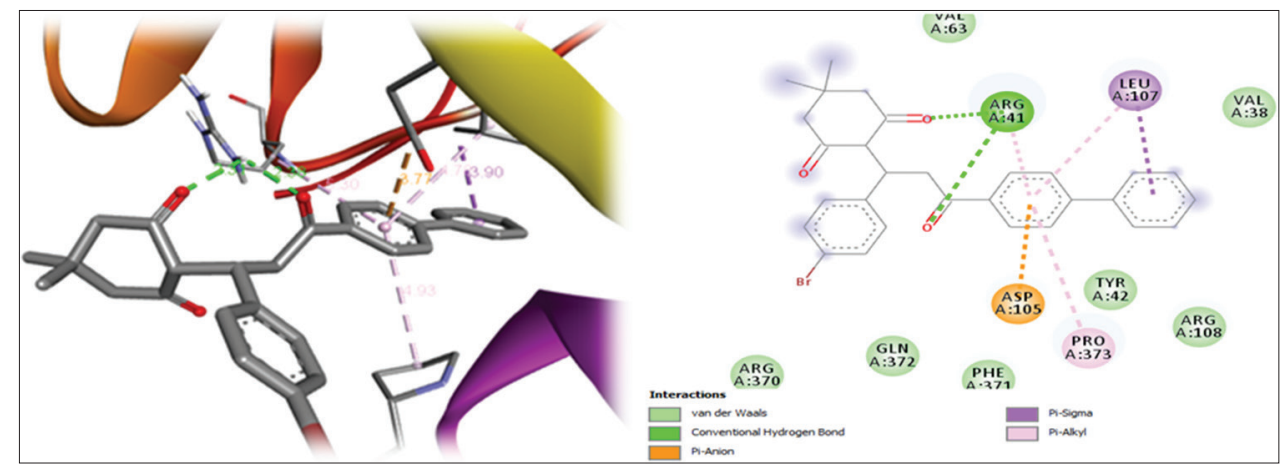

Fig. 2: Two-dimensional and three-dimensional images of compound 2-(1-(4-bromo phenyl)-3-oxo-3-diphenylpropyl)-5, 5-dimethylcyclohexane-1,3-dione (5c) docked with $2 \mathrm{ZOQ}$ protein

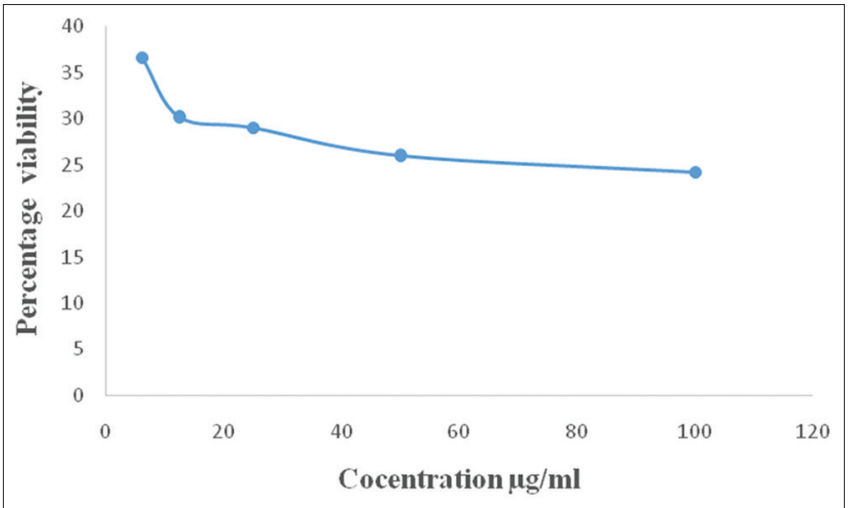

Fig. 3: In vitro anticancer activity screening for compound (5c) at low concentration
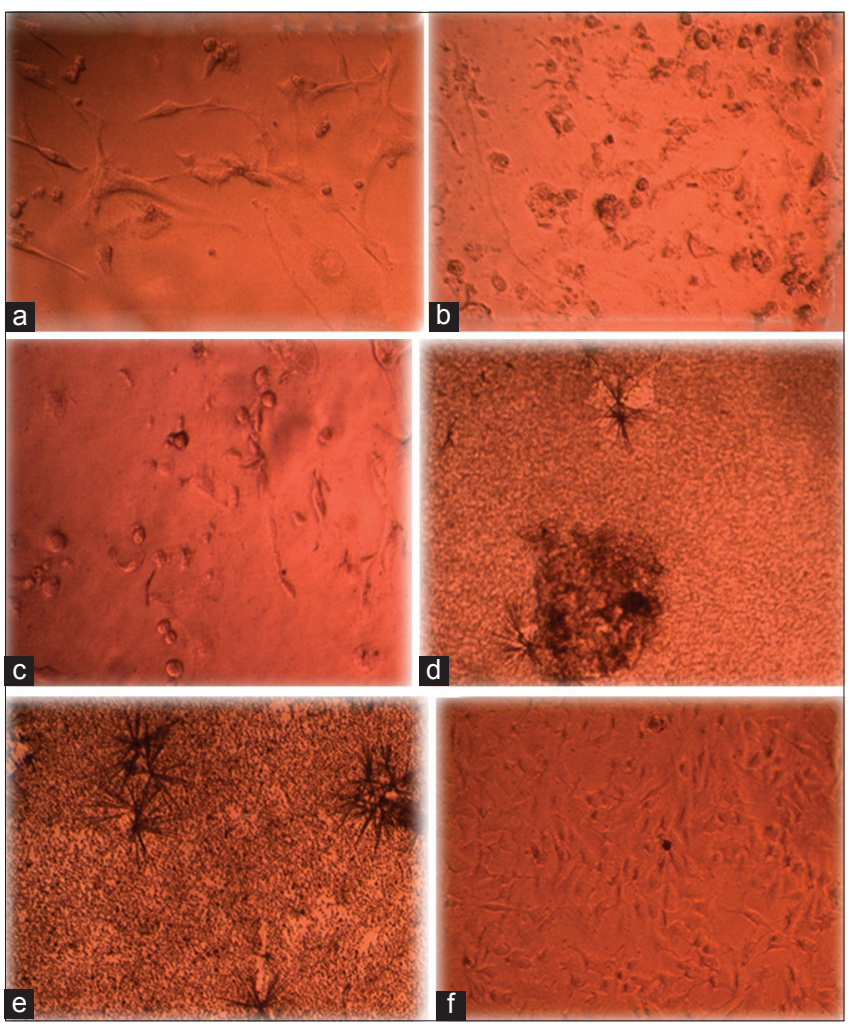

Fig. 4: An in vitro anticancer activity of compound $5 c$.

3,4-methylenedioxyamphetamine-MB-231 cells were incubated for $48 \mathrm{~h}$ in the presence of (a) $5 \mathrm{c}$ at $6.25 \mu \mathrm{g} / \mathrm{ml}$, (b) $5 \mathrm{c}$ at $12.5 \mu \mathrm{g} / \mathrm{ml}$, (c) $5 \mathrm{c}$ at $25 \mu \mathrm{g} / \mathrm{ml}$, (d) $5 \mathrm{c}$ at $50 \mu \mathrm{g} / \mathrm{ml}$, (e) $5 \mathrm{c}$ at $100 \mu \mathrm{g} / \mathrm{ml}$, (f) untreated control
Table 2: Binding affinity value and the conventional hydrogen bond of cyclohexane-1, 3-dione derivatives (5a-5h) against human breast cancer protein $2 \mathrm{ZOQ}$

\begin{tabular}{lll}
\hline Compound & $\begin{array}{l}\text { Binding } \\
\text { affinity (kcal/mol) }\end{array}$ & $\begin{array}{l}\text { Conventional hydrogen } \\
\text { bond }\end{array}$ \\
\hline $5 \mathrm{a}$ & -9.1 & 1 \\
$5 \mathrm{~b}$ & -8.8 & 1 \\
$5 \mathrm{c}$ & -9.6 & 1 \\
$5 \mathrm{~d}$ & -9.5 & 1 \\
$5 \mathrm{e}$ & -9.1 & - \\
$5 \mathrm{f}$ & -8.9 & 1 \\
$5 \mathrm{~g}$ & -8.7 & 1 \\
$5 \mathrm{~h}$ & -9.4 & 1 \\
\hline
\end{tabular}

Table 3: Antibacterial activity with different strains for cyclohexane-1,3-dione derivatives $(5 a-5 h)$

\begin{tabular}{lllllllllll}
\hline S. No. & Bacteria & \multicolumn{4}{l}{$\begin{array}{l}\text { Zone of inhibition at } \mathbf{2 . 5} \mathbf{~ m g} / \mathbf{m l} \\
\text { (diameter in } \mathbf{~ m m ) ~}\end{array}$} \\
\cline { 3 - 9 } & & $\mathbf{5 a}$ & $\mathbf{5 b}$ & $\mathbf{5 c}$ & $\mathbf{5 d}$ & $\mathbf{5 e}$ & $\mathbf{5 f}$ & $\mathbf{5 g}$ & $\mathbf{5 h}$ \\
\hline 1. & Staphylococcus aureus & 9 & 8 & 10 & 9 & 10 & 7 & 9 & 8 \\
2. & Streptococcus pyogenes & 12 & 10 & 10 & 10 & 12 & 11 & 12 & 11 \\
3. & Escherichia coli & 12 & 8 & 9 & 11 & 11 & 11 & 10 & 10 \\
4. & Pseudomonas sp. & 12 & 7 & 10 & 11 & 11 & 10 & 10 & 9 \\
\hline
\end{tabular}

Table 4: Antifungal activity test for cyclohexane-1,3-dione derivatives $(5 a-5 h)$

\begin{tabular}{|c|c|c|c|c|}
\hline \multicolumn{5}{|c|}{ Antimicrobial susceptibility testing against Candida albicans } \\
\hline \multirow[t]{2}{*}{ S. No. } & \multicolumn{4}{|c|}{ Zone of inhibition (diameter in $\mathrm{mm}$ ) } \\
\hline & Compound & $10 \mathrm{mg} / \mathrm{ml}$ & $5 \mathrm{mg} / \mathrm{ml}$ & $2.5 \mathrm{mg} / \mathrm{ml}$ \\
\hline 1. & $5 a$ & 16 & $13 \mathrm{~mm}$ & $12 \mathrm{~mm}$ \\
\hline 2. & $5 b$ & $14 \mathrm{~mm}$ & $13 \mathrm{~mm}$ & $11 \mathrm{~mm}$ \\
\hline 3. & $5 c$ & $13 \mathrm{~mm}$ & $11 \mathrm{~mm}$ & $9 \mathrm{~mm}$ \\
\hline 4. & $5 d$ & $12 \mathrm{~mm}$ & $10 \mathrm{~mm}$ & $9 \mathrm{~mm}$ \\
\hline 5. & $5 e$ & $13 \mathrm{~mm}$ & $11 \mathrm{~mm}$ & $10 \mathrm{~mm}$ \\
\hline 6. & $5 f$ & $12 \mathrm{~mm}$ & $12 \mathrm{~mm}$ & $10 \mathrm{~mm}$ \\
\hline 7. & $5 g$ & $11 \mathrm{~mm}$ & $10 \mathrm{~mm}$ & $11 \mathrm{~mm}$ \\
\hline 8. & $5 \mathrm{~h}$ & $14 \mathrm{~mm}$ & $12 \mathrm{~mm}$ & $10 \mathrm{~mm}$ \\
\hline
\end{tabular}

MDA-MB-231 cell line. In the ligand, cyclohexane-1,3-dione derivative (5a-5h) values are shown in Table 2. 2D and 3D images of compound 5c are shown in Fig. 2. Compound 5c showed one conventional hydrogen bond interaction with the same amino acid (ARG A: 41) formed at carbonyl group of the biphenyl moiety and dimedone moiety. This compound has only one alkyl and pi-alkyl interaction with PRO A: 373 formed at the benzene ring of biphenyl moiety. 
The synthesized compounds ( $5 \mathrm{a}-5 \mathrm{~h}$ ) were subjected to insilico analysis against different bacterial proteins (1UAG, 3UDI, 2X50). Compound $5 \mathrm{c}$ showed binding scores as $-9.4,-9.6$, and $-9.1 \mathrm{kcal} / \mathrm{mol}$ against $1 \mathrm{UAG}$, $3 \mathrm{UDI}$, and $2 \mathrm{X} 50$ proteins indicating a very good affinity. In a similar way when these compounds were docked against the human breast cancer protein 2ZOQ compound 5c showed a binding score of $-9.6 \mathrm{kcal} / \mathrm{mol}$ and thereby indicated that it is a good candidate for further studies. Hence, in vitro studies (MTT assay of antimicrobial studies) were carried out to confirm its activities.

MTT assay study for compound 2-(1-(4-bromophenyl)-3-oxo-3diphenylpropyl)-5, 5-dimethyl cyclohexane-1,3-dione derivative From this result, the in vitro anticancer activity was performed by MTT assay method for compound 2-(1-(4-bromophenyl)-3-oxo-3diphenylpropyl)-5,5-dimethyl cyclohexane-1,3-dione (5c). Based on binding affinity score, the in vitro anticancer activity was done using various concentrations $(100,50,25,12.5$, and $6.25 \mu \mathrm{g} / \mathrm{ml})$ of the sample $5 c$ against the MDA-MB-231 cell line. From this result, synthesized compound $5 c$ exhibited a good activity at low concentration $(6.25 \mu \mathrm{g} / \mathrm{ml})$. The $\mathrm{LC}_{50}$ value of this compound is $10.31 \pm 0.003 \mu \mathrm{g} / \mathrm{ml}$. Experiments were conducted in triplicate and the mean value was calculated.

\section{Antimicrobial activity}

The new series of cyclohexane-1,3-dione derivatives (5a-5h) were screened for antimicrobial activity. The results are shown in Table 3. From Table 3, compound 5c showed a good zone of inhibition against Staphylococcus aureus, Streptococcus pyogenes, and Pseudomonas sp. Compound 5 a showed a good zone of inhibition against $S$. pyogenes, Escherichia coli, and Pseudomonas sp. Compound $5 \mathrm{~b}$ showed a good zone of inhibition against $S$. pyogenes. Compound $5 \mathrm{~d}$ showed a good zone of inhibition against E. coli and Pseudomonas sp. Compound 5e showed a good zone of inhibition against $S$. pyogenes. Compound $5 \mathrm{f}$ showed a good zone of inhibition against $S$. pyogenes and E. coli. Compound $5 \mathrm{~g}$ showed a good zone of inhibition against $S$. pyogenes. Compound $5 \mathrm{~h}$ showed a good zone of inhibition against $S$. pyogenes. These compound values are shown in Table 3.

The cyclohexane-1,3-dione derivatives were screened for antifungal activity at different concentrations such as 10,5 , and $2.5 \mathrm{mg} / \mathrm{ml}$. The results are shown in Table 4. From Table 4, compound 5a shown the good zone of inhibition against Candida albicans $(12 \mathrm{~mm}$ at $2.5 \mathrm{mg} / \mathrm{ml})$.

\section{CONCLUSION}

The new series of cyclohexane-1,3-dione derivatives were synthesized by Michal addition reaction. The structures of the cyclohexane-1,3dione derivatives were confirmed by FT-IR, ${ }^{1} \mathrm{H}$, and ${ }^{13} \mathrm{C}$ NMR spectral data. The docking study was carried out for cyclohexane-1,3-dione derivatives (5a-5h) using bacterial proteins (1UAG, 3UDI, and 2X50) and cancer protein (2ZOQ). From this result, the receptor and the compound have greater potency of interactions in a binding site. Especially, the compound 5c showed good binding score with cancer protein. For that reason, anticancer (human breast adenocarcinoma) activity was studied only compound $5 \mathrm{c}$. The $\mathrm{LC}_{50}$ value of compound $5 \mathrm{c}$ is $10.3134 \mu \mathrm{g} / \mathrm{ml}$. Furthermore, antimicrobial studies were carried out for cyclohexane 1,3-dione derivatives (5a-5h). From the antimicrobial and antifungal screening, it was observed that all compounds exhibited good activity against Gram-positive and Gram-negative strains. The present research work could be useful to develop the in vivo studies of the synthesized compounds.

\section{ACKNOWLEDGMENT}

We thank the Biogenix Research Center for conducting the MDA-MB-231 cell line anticancer assay for our compound 2-(1-(4-bromophenyl)-3oxo-3-diphenylpropyl)-5,5-dimethyl cyclohexane-1,3-dione.

\section{AUTHORS' CONTRIBUTIONS}

Designed the experiments: Raja Chinnamanayakar and Ezhilarasi M. R. Performed the reactions: Raja Chinnamanayakar.
Performed the antimicrobial activity: Kulandhaivel. Performed the molecular docking study: Raja Chinnamanayakar. Performed the anticancer activity: Biogenix Research Center, Trivandrum. Wrote the paperwork: Raja Chinnamanayakar, Ezhilarasi M.R, and Prabha B. Revised the article: Ezhilarasi M.R and Prabha B.

\section{CONFLICTS OF INTEREST}

We declare that we have no conflicts of interest.

\section{REFERENCES}

1. Al Harun Rashid MD, Deepak Bharadwaj PV, Majumder S, Mandal V, Pal M, Mandal SC, Thandavarayan RA. Antioxidant and anticancer activity of extract and fractions obtained from Diospyros melanoxylon roxb. leaves and correlation with their polyphenolic profiles. Int J Pharm Pharm Sci 2018;10:6-16.

2. Mendes N, Tortosa F, Valente A, Marques F, Matos A, Morais TS, et al. In vivo performance of a ruthenium-cyclopentadienyl compound in an orthotopic triple negative breast cancer model. Anticancer Agents Med Chem 2017;17:126-36.

3. Harun SNA, Israf DA, Tham CL, Lam KW, Cheema MS, Md Hashim NF, et al. The molecular targets and anti-invasive effects of 2,6-bis-(4-hydroxyl-3methoxybenzylidine) cyclohexanone or BHMC in MDA-MB-231 human breast cancer cells. Molecules 2018;23. pii: E865.

4. Küçükgüzel ŞG, Şenkardeş S. Recent advances in bioactive pyrazoles. Eur J Med Chem 2015;97:786-815.

5. Kumar V, Kaur K, Gupta GK, Sharma AK. Pyrazole containing natural products: Synthetic preview and biological significance. Eur J Med Chem 2013;69:735-53

6. Claisen L, Claparede A. Condensation von ketonen mit aldehyden. Ber Dtsch Chemischen Ges 1881;14:2460-8.

7. Alwash AH, Mahdi AM, Al-Karagully HJ. Synthesis, characterization, and antimicrobial evaluation of new $\mathrm{N}$-phenylcinnamamide derivatives linked to aspirin and ibuprofen. Asian J Pharm Clin Res 2018;11:443-6.

8. Umadevi A, Kumari C, Ajith Kumar P, Hameemath Shaman Nasmin AM, Divya K, Hisana PV. Development and evaluation of polyherbal gel for antifungal activity. Int J Curr Pharm Res 2018;10:40-3.

9. Trost BM, Fleming I. Comprehensive Organic Synthesis. Vol. 1-9. New York, USA: Pergamon Press; 1991.

10. Basavaiah D, Rao AJ, Satyanarayana T. Recent advances in the BaylisHillman reaction and applications. Chem Rev 2003;103:811-92.

11. Sammelson RE, Kurth MJ. Carbon-carbon bond-forming solid-phase reactions. Part II. Chem Rev 2001;101:137-202.

12. Huddleston RR, Krische MJ. Enones as latent enolates in catalytic processes: Catalytic cycloreduction, cycloaddition, and cycloisomerization. Synlett 2003;6:12-21.

13. Gibson SE, Stevenazzi A. The pauson-khand reaction: The catalytic age is here! Angew Chem Int Ed Engl 2003;42:1800-10.

14. Moreno-Mañas M, Pleixats R. Formation of carbon - carbon bonds under catalysis by transition-metal nanoparticles. Acc Chem Res 2003;36:638-43

15. Asiri AM. Synthesis and characterization of dyes exemplified by 2-arylidene-1-dicyanomethyleneindane. Dyes Pigm 1999;42:209-13.

16. Ballini R, Bosica G. Nitroaldol reaction in aqueous media: An important improvement of the henry reaction. J Org Chem 1997;62:425-7.

17. Tang Z, Yang ZH, Chen XH, Cun LF, Mi AQ, Jiang YZ, et al. A highly efficient organocatalyst for direct aldol reactions of ketones with aldehydes [corrected]. J Am Chem Soc 2005;127:9285-9.

18. Chi Y, Gellman SH. Diphenylprolinol methyl ether: A highly enantioselective catalyst for Michael addition of aldehydes to simple enones. Org Lett 2005; 7:4253-6.

19. Liu Y, Liu X, Wang M, He P, Lin L, Feng X, et al. Enantioselective synthesis of 3,4-dihydropyran derivatives via organocatalytic michael reaction of $\alpha, \beta$-unsaturated enones. J Org Chem 2012;77:4136-42.

20. Tiwary BK, Pathak RK, Pradhan K, Nanda AK, Bothra AK, Chakraborty R. Evaluation of drug candidature of some quinazoline$4-(3 \mathrm{H})$-ones as an inhibitor of human dihydrofolate reductase enzyme: Molecular docking and in silico studies. Int J Pharm Pharm Sci 2014;6 Suppl 20:393-400.

21. Wang SH, Wang XS, Da-Qing SH, Shu-Jiang TU. Michael addition reaction of dimedone and chalcone catalysed by KF/A12O3. Chin J Org Chem 2003;23:1146-8

22. Chinnamanayakar R, Ezhilarasi MR, Prabha B, Kulandhaivel M. 
In vitro Antimicrobial activity and in silico activity of 1-thiocarbamoyl substituted pyrazole derivatives. Asian J Chem 2018;30:783-9.

23. Sri Dharani R, Ranjitha R, Sripathi R, Ali Muhammad KS, Ravi S. Docking studies in target proteins involved in antibacterial action mechanisms: Alkaloids isolated from Scutellaria genus. Asian J Pharm
Clin Res 2016;9:121-5.

24. Talarico LB, Zibetti RG, Faria PC, Scolaro LA, Duarte ME, Noseda MD, et al. Anti-herpes simplex virus activity of sulfated galactans from the red seaweeds Gymnogongrus griffithsiae and Cryptonemia crenulata. Int J Biol Macromol 2004;34:63-71. 